\title{
Human immunodeficiency virus associated spondyloarthropathy: pathogenic insights based on imaging findings and response to highly active antiretroviral treatment
}

\author{
D McGonagle, S Reade, H Marzo-Ortega, W Gibbon, P O'Connor, A Morgan, \\ R Melsom, E Morgan, P Emery
}

\begin{abstract}
The pathogenesis of human immunodeficiency virus (HIV) associated spondyloarthropathy (SpA) is poorly understood. In this case report a patient is described with severe HIV associated reactive arthritis, who on magnetic resonance imaging and sonographic imaging of inflamed knees had extensive polyenthesitis and adjacent osteitis. The arthritis deteriorated despite conventional antirheumatic treatment, but improved dramatically after highly active antiretroviral treatment, which was accompanied by a significant rise in CD4 T lymphocyte counts. The implications of the localisation of pathology and effect of treatment for pathogenic models of SpA and rheumatoid arthritis in the setting of HIV infection are discussed.

(Ann Rheum Dis 2001;60:696-698)
\end{abstract}

Rheumatology and

Rehabilitation

Research Unit,

University of Leeds, 36

Clarendon Road,

Leeds LS2 9NZ, UK

D McGonagle

$S$ Reade

H Marzo-Ortega

$P$ Emery

A Morgan

Department of Radiology, The Leeds General Infirmary, Great George Street, Leeds LS1 3EX, UK

W Gibbon

P O'Connor

Rheumatology

Department, St Luke's Hospital, Little Horton

Lane, Bradford

BD5 0NA, UK

R Melsom

Department of Genitourinary

Medicine, St Luke's

Hospital, Little Horton

Lane, Bradford

BD5 0NA, UK

E Morgan

Correspondence to:

Professor Emery

Accepted 26 September 2000
The musculoskeletal manifestations of human immunodeficiency virus (HIV) infection have intrigued doctors for several years. ${ }^{1}$ Of special interest are the seronegative spondyloarthropathies ( $\mathrm{SpA})$, which seem to be more common, more severe, and more resistant to antirheumatic treatment in the setting of advanced HIV infection. ${ }^{2}{ }^{3}$ In contrast to these observations, rheumatoid arthritis (RA) is no more common in the setting of HIV and, although some reports suggest that RA may also deteriorate after HIV, other reports have documented improvement or even clinical remission. ${ }^{4}$ The basis for the divergent clinical patterns of RA and $\mathrm{SpA}$ in the setting of $\mathrm{HIV}$ is poorly defined. This case report describes a patient with advanced HIV infection and associated SpA oligoarthritis with a distinctive pattern of pathology on imaging. Although conventional antirheumatic treatment failed, his arthritis eventually responded to the addition of a protease inhibitor to his double combination treatment of nucleoside analogues. The possigenesis of SpA and RA in the setting of HIV are discussed.

\section{Case report}

A 31 year old homosexual man was admitted to hospital in January 1997 with severe bilateral knee and wrist swelling associated with two hours of early morning stiffness that had developed over the preceding two months. $\mathrm{He}$ ble implications of these findings for the patho- had no pain or stiffness in his spine or other joints and did not have a history of psoriasis. He was diagnosed HIV positive in 1988 but did not then require treatment. On routine follow up in 1994 he was found to have a low CD4 count (CD4 count, $40 \times 10^{6} / 1$; normal range, $\left.500-1750 \times 10^{6} / 1\right)$. He declined treatment with zidovudine but, in view of the low CD4 count, Pneumocystis carinii (PC) prophylaxis was started with Septrin. He presented acutely in 1995 with circinate balanitis and diarrhoea. Although an infectious aetiological agent was not identified he eventually settled on antibiotic treatment. A few months later, treatment with a single drug, didanosine, was started after he became systemically unwell with fever, cough, arthralgia, weight loss, and balanitis. The treatment failed to settle him and he was given instead two different nucleoside analogues (lamivudine and stavudine). Despite clinical improvement, the CD4 count remained low at $20 \times 10^{6} / 1$.

On examination at the time of admission, his left wrist and both knees were tender, hot, and swollen. There was also a rash on his penis consistent with circinate balanitis, necrotic mouth ulcers, and seborrhoeic dermatitis on his face. He was apyrexial. A thorough infection screen, including checks for opportunistic infections, failed to yield any positive results. Blood results were as follows: haemoglobin $116 \mathrm{~g} / 1$, white cell count $2.3 \times 10^{9} / 1$, with a CD4 T lymphocyte count of $20 \times 10^{6} / 1$, platelets $457 \times 10^{9} / 1$, C reactive protein (CRP) 121 $\mathrm{mg} / \mathrm{l}$, HLA-B27 positive, and normal serum urate. Standard radiographs of both knee joints were normal. Routine screening for common opportunistic infections such as atypical mycobacteria, gonoconocci, etc, was negative. $\mathrm{Mi}$ croscopy of the synovial fluid aspirate showed no crystals and, once culture had proved negative, $40 \mathrm{mg}$ of intra-articular methylprednisolone was administered to each knee and wrist. Treatment was also started with indometacin, tramadol, and sulfasalazine, which was titrated up to a dose of $2 \mathrm{~g}$ twice daily. In the following three weeks he did not settle and had persistent severe joint swelling; he also developed plantar fasciitis and keratoderma blenorrhagicum.

Because of the failure of treatment and degree of knee swelling, further imaging of both knees was arranged to determine the extent of inflammation. Fat suppressed magnetic resonance imaging (MRI) and sonographic assessment of both knees were 

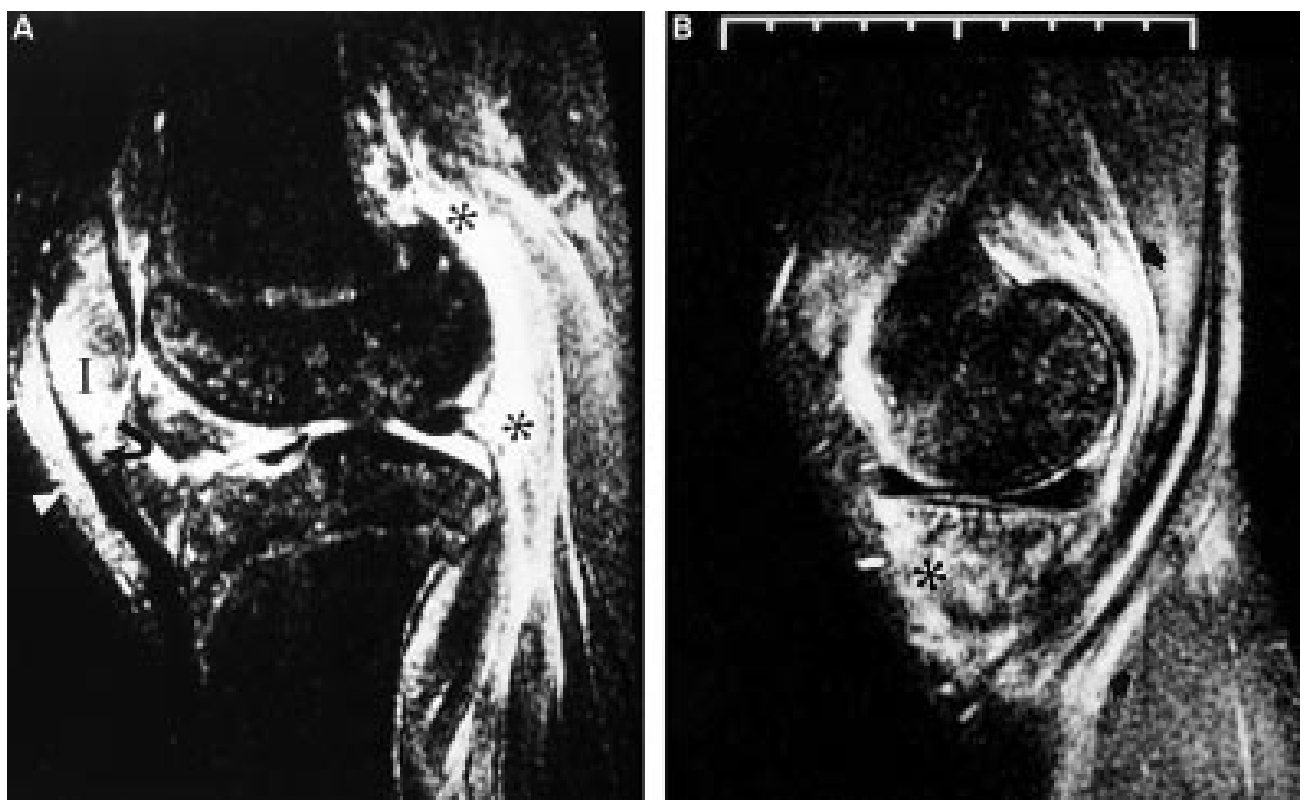

Figure 1 (A) Sagittal fat suppressed MR image of the left knee showing extensive bone oedema at several sites. It is maximal at the patella (curved black arrow), tibial plateau, and femoral condyle (asterisks) and anterior to the patellar tendon origin (white arrow heads). (B) Adjacent image from the medial aspect of the same joint showing bone oedema at the tibial plateau (black asterisk) with extensive extracapsular oedema (black arrows).

performed as previously described. ${ }^{5}$ Both MRI and sonography confirmed bilateral knee joint effusion and synovitis. However, the most striking finding of the MRI in both knee joints was severe bone marrow and soft tissue oedema adjacent to several entheseal insertions, which was compatible with polyenthesitis as shown in figs $1 \mathrm{~A}$ and $\mathrm{B}$. Both knees also had diffuse and extensive bone oedema at the tibia plateau, which extended some way from entheseal insertions. These MRI findings were corroborated on sonography where an erosive polyenthesitis was evident with erosions visible on both longitudinal and transverse planes as

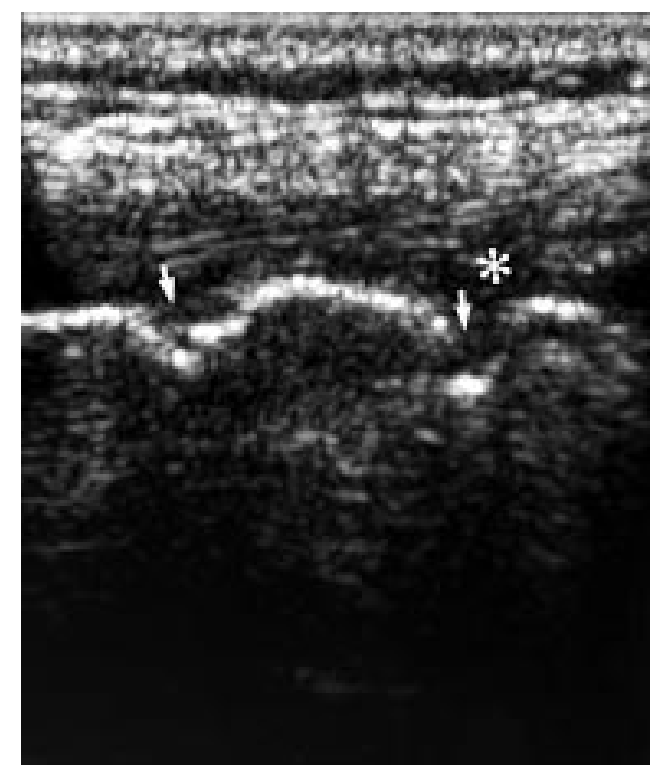

Figure 2 Sonographic image of the medial aspect of the same joint showing the medial collateral ligament insertion. There is ligament thickening and oedema (white asterisk) and bone erosion (white arrows). Similar patterns of erosive enthesitis were also evident in the lateral collateral ligaments and patellar tendons. seen in fig 2. The medial collateral ligaments in both knees were thickened, oedematous, and associated with bone erosion at the site of the MRI demonstrable bone oedema as in fig 2 . Enthesitis was also shown sonographically at the lateral collateral ligament insertions and patellar tendon origin. The entheseal changes were extensive and were closely juxtaposed to the synovial cavity.

Ritonavir, a protease inhibitor was added to his treatment with stavudine and lamivudine. This was accompanied by a rise in the CD4 count to $320 \times 10^{6} / 1$, a fall in the viral load, and CRP normalisation and in the following two weeks his arthropathy settled. The patient was discharged on triple antiretroviral treatment and sulfasalazine. He remains in remission at two years' follow up.

\section{Discussion}

This case shows that the $\mathrm{SpA}$ associated oligoarthropathy in advanced HIV infection may be associated with severe polyenthesitis and that the relatively resistant arthropathy may settle in response to highly active antiretroviral treatment (HAART). Enthesitis is well described in HIV associated $\mathrm{SpA}^{6}$, but such anatomical factors have not previously been considered in relation to the divergent clinical course of synovial joint pathology of $\mathrm{RA}$ and $\mathrm{SpA}$ in HIV.

The anatomical findings of this study suggest fundamentally different models for the divergent behaviour of $\mathrm{SpA}$ (more common and severe) and RA (may go into remission) in patients with advanced HIV, as shown in table 1. The enthesis and adjoining structures are sites of increased biomechanical traction forces and tissue microtrauma. ${ }^{78}$ Biomechanical stress with resultant microtrauma is likely to lead to a healing response, which is proinflammatory. ${ }^{9}$ Furthermore, the resultant alteration 
Table 1 The proposed major immunological, bacteriological, and anatomical factors in $R A$ and SpA in the setting of HIV infection

\begin{tabular}{ll}
\hline Rheumatoid arthritis & Spondyloarthropathy \\
\hline $\begin{array}{l}\text { MHC association-HLA-DR4 } \\
\text { CD4 T cells which contribute to inflammation } \\
\text { are depleted in advanced HIV }\end{array}$ & $\begin{array}{l}\text { MHC association-HLA-B27 } \\
\text { CD8 T cells also diminish but are spared } \\
\text { compared with CD4 cells }\end{array}$ \\
$\begin{array}{l}\text { Primary target tissue } \\
\text { The synovial membrane }\end{array}$ & $\begin{array}{l}\text { Primary target tissue } \\
\text { Sites of increased biomechanical stress in the } \\
\text { joints, especially the enthesis, adjacent marrow, } \\
\text { capsules }\end{array}$ \\
Triggers-unknown & $\begin{array}{l}\text { Triggers - bacteria/virus (including HIV) } \\
\text { Rheumatoid factors? }\end{array}$ \\
Infection? & $\begin{array}{l}\text { Genitourinary and bowel inflammation may be } \\
\text { comener in homosexuals, thus allowing }\end{array}$ \\
& greater access of bacteria to the circulation \\
\hline
\end{tabular}

in vascularity at these sites may favour the deposition of bacteria or their constituent molecules. ${ }^{10}$ This is especially the case because genitourinary infections are common in homosexual men and enteric infections are more common in patients with advanced HIV infection. These microbial and host factors could combine to give an inflammatory reaction at these sites of stress. Because cytotoxic CD8 T cells are spared compared with CD $4 \mathrm{~T}$ cells then the former could mediate their cytotoxicity through hitherto unidentified peptides bound to HLA-B27.

However, if RA is considered primarily an immune mediated disease that targets the synovial membrane then it should be no commoner in HIV especially because CD4 T lymphocytes are depleted, as indicated in table 1.

The management of SpA associated arthritis in the setting of HIV infection poses some difficulty. ${ }^{11}$ HIV associated SpA is often undifferentiated. Clinical recognition and identification of a specific pathogen may be difficult and, as in the present case, treatment may also prove difficult. The addition of ritonavir to his combination treatment of two nucleoside analogues had a dramatic effect on our patient. Although this might have represented the natural history of the arthritis or a response to sulfasalazine, it is interesting to speculate that the triple treatment combination might have contributed to the patient's recovery. Recently, it has been suggested that HAART is effective in preventing AIDS defining illness ${ }^{12}$ and it is possible, as in our case, that this treatment might have contributed to the alleviation of the arthropathy. There are two possible mechanisms for this. Firstly, some authors have suggested that HIV could be prominent in joint tissues $^{13}$ and indeed the role of HAART in the patient's recovery may be related to inhibition of HIV itself at these sites. ${ }^{14}$ Secondly, the HIV inhibition might have allowed sufficient immune recovery to control a pathogen which was contributing to genitourinary or intestinal infection which was the trigger for disease. It is possible that the resistance of HIV associated
SpA could relate to continued infection with micro-organisms and that the HAART treatment indirectly alleviated this by raising the CD4 cell count, leading to a more effective immune response. Whichever of these explanations proves to be the case the infectious trigger seems to act primarily at the enthesis.

In conclusion, the imaging findings and response to treatment in this case may shed light on a pathogenic model for HIV associated SpA. The biomechanical factors resulting in disease localisation, the increased access of infectious agents to the circulation, and the relative preservation of the CD8 $\mathrm{T}$ cell repertoire may explain why disease is more common and severe. These anatomical observations also have implications for pathogenic mechanisms for inflammatory arthritis in general.

Three pathogenic mechanisms are proposed for $\mathrm{SpA}$ in the setting of HIV infection: (a) exposure to bacterial triggers is increased; (b) CD8 T cells are relatively spared; and (c) biomechanical factors may be important in primary disease localisation. In comparison, RA may be more immunologically mediated, with rheumatoid factors and CD4 T cells contributing to inflammation. This difference may explain why RA is no commoner in HIV and why it may even go into remission.

1 Kay BR. Rheumatological manifestations of infection with human immunodeficiency virus. Ann Intern Med 1989;111:158-67.

2 Arnett FC, Reveille JD, Duvic M. Psoriasis and psoriatic Arnett FC, Reveille JD, Duvic M. Psoriasis and psoriatic
arthritis associated with human immunodeficiency virus infection. Rheum Dis Clin North Am 1991;17:59-78.

3 Golbus J. Rheumatic disease and AIDS. An interesting but mysterious relationship. Postgrad Med 1992;92:99-107.

4 Muller-Ladner U, Kriegsmann J, Gay RE, Koopman WJ, Gay S, Chatham WW. Progressive joint destruction in a human immunodeficiency virus-infected patient with rheumatoid arthritis. Arthritis Rheum 1995;38:1328-6.

5 McGonagle D, Gibbon W, O'Connor P, Green M, Pease C, Emery P. Characteristic MRI entheseal changes of knee synovitis in spondyloarthropathy. Arthritis Rheum 1998; 41:694-700.

6 Rowe IF, Forster SM, Seifert MH, Youle MS, Hawkins DA, Lawrence AG, et al. Rheumatological lesions in individuals with human immunodeficiency virus infection. Q J Med

7 Benjamin M, Ralphs JR. Tendons and ligaments-an Benjamin M, Ralphs JR. Tendons and ligan
overview. Histol Histopathol 1997;12:1135-44.

8 Rufai A, Ralphs JR, Benjamin M. Structure and histopathology of the insertional region of the human Achilles tendon. J Orthop Res 1995;13:585-93.

9 Singer AJ, Clark RA. Cutaneous wound healing. N Engl J Med 1999;341:738-46.

10 Schulz LC, Schaening U, Pena M, Hermanns M. Borderline-tissues as sites of antigen deposition and persistence- a unifying concept for rheumatoid inflammation? Rheumatol Int 1985;5:21-27.

11 Schewe CK, Kellner H. Rapidly progressive seronegative spondylarthropathy with atlantodental subluxation in a
patient with moderately advanced HIV infection. Clin Exp Rheumatol 1996;14:83-5.

12 Mocroft A, Katlama C, Johnson AM, Pradier C, Antunes F, Mulcahy F, et al. AIDS across Europe, 1994-98: the Mulcahy F, et al. AIDS across Europe,
EuroSIDA study. Lancet 2000;356:291-6.

13 Cuellar ML, Espinoza LR. Human immunodeficiency virus associated spondyloarthropathy: lessons from the third associated spondyloarthropathy: less
world. J Rheumatol 1999;26:2071-3.

14 Bentin J, Feremans W, Pasteels JL, Hauzeur JP, Menu R, Appelboom T. Chronic acquired immunodeficiency syndrome-associated arthritis: a synovial ultrastructural study. Arthritis Rheum 1990;33:268-7. 